\title{
Barriers of Growth Measurements of Critically-Ill Children As Expressed By Nurses in the Pediatric Intensive Care Unit
}

\author{
Gehan EL Nabawy Ahmed \\ Lecturer of Pediatric Nursing, Faculty of Nursing, Mansoura University
}

\begin{abstract}
Children's weight and height measurements are used regularly within the critical care setting whether for calculation of drug doses, nutritional intake, ventilator settings or calibration of cardiac output monitoring. These parameters are often obtained by critical care staff, especially nurses. Errors in these measurements have the potential to cause harm either from errors in drug calculations, inappropriate ventilatory settings, underfeeding or overfeeding. This study aimed to assess nurses' perception regarding barriers of growth measurements of critically-ill children in the pediatric intensive care unit. Descriptive correlative research design was used. The study involved 60 nurses from Pediatric Intensive Care Unit (PICU) at Children's University Hospital in Mansoura city, Egypt. Interview questionnaire sheet was developed by the researcher to collect relevant data and consisting of 4 parts. The study concluded that the most perceived barriers mentioned by nurses were mechanical ventilation, in ability of the child to stand or communicate, lack of awareness on the importance of growth measurements and its impact on child care and nurses' workload. The study recommended that emphasis on the importance for educating nurses about the importance of obtaining timely growth measurements of critically ill children. Moreover, develop strategies with evidence-based guidelines and practice standards which necessary to overcome myths about common barriers of growth measurements in the PICU.
\end{abstract}

Key wards: Growth or anthropometric measurements, nurses, barriers, critically ill children.

\section{Introduction}

Weight and stature (standing height or recumbent length) are the most commonly obtained growth measurements in infants and children (Sentongo, 2010). An accurate weight and height is essential in the assessment of a critically ill child presenting pediatric intensive care unit (Bloomfield et al, 2006 and Maskin et al, 2010). The estimation of weight for critically ill children is essential for safe drug-prescribing and selecting the correct-sized equipment (O'Leary et al, 2017). Additionally, estimation of a child's weight is often necessary in the emergency department for assessment of clinical status and to enable accurate drug dosage, equipment size and counter shock voltage calculation during pediatric resuscitation (Krieser et al, 2007, Buckley et al, 2012 and Graves et al, 2014). Moreover, measurement of weight during the preoperative and anesthesia is very important because it is dependent to drug dosing, ventilation parameters, airway control, IV problems, and fluid management. Thus, inaccurate estimation of body weight in critical state is potentially dangerous (Nasiri\& Nasiri, 2013).

Knowledge of child' height is essential for daily practice in the critical sitting, for either assessment of renal function, calculate body mass index, ideal body weight, determination of drug doses, calculating cardiac function indices, or tidal volume setting (Martin et al, 2011). Because it is well established that child' lungs are well correlated with their height (Neto et al, 2012), accurate tidal volume setting should be based on height to avoid acquired acute lung injury and to improve outcome (Lellouche et al, 2012).L'her et al, (2016) added that, in intensive care unit, measuring height is essential for patients undergoing mechanical ventilation.

Both weight and height are required to estimate body surface area and body mass index. Thus, accurate estimation or measurement of height and weight of critically ill patients may be important for optimum clinical care. Subsequent and serial measurements of weight during a PICU admission are essential to identify and understand changes in fluid status (Bloomfield et al, 2006). These children may be present water and electrolyte imbalance, kidney or liver failure with edema, rendering weight a less reliable marker of nutritional status. Finally, children with chronic disease often present compromised height due to malnutrition, and if anthropometric criteria are rigorously applied, these patients may be erroneously classified as well-nourished or even overweight (Grippa et al, 2017). The lack of accurate and consistent growth data cause marked risks to the safe management and recovery of a critically ill child. Ultimately, lack of or incorrect anthropometric measurements can lead to inaccurate or inadequate therapies, which can adversely affect clinical outcomes such as duration of mechanical ventilation, length of PICU stay, and patient survival (Hulst et al, 2004). O'Leary et al, (2017) added that both overestimation and underestimation of a child's weight may lead to suboptimal medication dosing and related morbidity or mortality.

Despite the known limitations of anthropometric methods when applied to ill children, anthropometry remains widely used as a tool for assessing clinical status in this pediatric group (Menezes, Leite\&Nogueira, 2012). One of the great difficulties in the assessment of growth measurements of critically-ill children is choosing the best method. Moreover, the difficulties may be due to the patient's clinical condition, the hemodynamic alterations or body composition modification (Skillman \&Wischmeyer, 2008).Partridge et al, (2009) pointed that variability in clinical standards, wide inconsistencies in staff training and lack of equipment accuracy make the reliability of anthropometric measurements questionable.

Many of these perceived barriers could be overcome by establishing standardized guidelines for nurses. For example, the availability of newer technologies such as patient beds with the capability of measuring weight and the use of overhead lifts enable members of the clinical team to work together to obtain weights in a timely manner at PICU admission. Education on the importance of stature in clinical care and the use of appropriate tools and techniques to measure stature should be encouraged. Critically ill children with contractures of long bones pose special challenges for measurements of 
stature. In such circumstances, skilled providers such as registered dieticians should be consulted to obtain limb-length measurements as an alternative method to determine stature (Wakeham et al, 2013). Irving et al, (2015) added that, when growth measurements are simply obtaining without thoughtful discussion among the clinical team and use in patient care can lead to diminished perception of the importance of the measurements. This can result in inconsistency in obtaining anthropometric measurements or in not obtaining them at all. Giving performance feedback to nursing staff on prescribing and obtaining anthropometric measurements is important to discourage estimation of these measurements, aid clinical care, and enhance child safety.

\section{Significance}

Growth measurements and anthropometric measurements are terms which sometimes used interchangeably.Children's weight and height measurements are the most measurements that used regularly within the critical care setting whether for calculation of drug doses, nutritional intake, ventilator settings or calibration of cardiac output monitoring. These parameters are often obtained by critical care staff, especially nurses. Errors in these estimations have the potential to cause harm either from errors in drug calculations, inappropriate ventilatory settings or underfeeding or overfeeding.Actual measurement of weight and height on critically ill children are not always accomplished because those children are frequently admitted as emergencies, are not ambulant, or may be unable to communicate, and these factors, in combination, can make accurate measurements difficult. Furthermore, the great difficulties in the assessment of growth measurements of critically- ill children are found, whether due to the child's clinical condition, the hemodynamic alterations, body composition modification or even the lack of staff awareness on the importance of appropriately performing measurement. So, the novelty of this study is to assess nurses' perception regarding barriers of growth measurements of critically-ill children in the pediatric intensive care unit.

\section{Aim}

This study aimed to assess nurses' perception regarding barriers of growth measurements of critically-ill children in the pediatric intensive care unit.

\section{Research questions}

The following research questions are posed:

What are the barriers of growth measurements of critically ill children in the pediatric intensive care unit?

Is there association between nurses' general characteristics and their perceived barriers of growth measurements of critically ill children in the pediatric intensive care unit?

\section{Methodology}

\section{Research design}

Descriptive correlative research design was used.

\section{Setting}

The study was conducted at pediatric intensive care unit (PICU) at Children's University Hospital in Mansoura city, Egypt. Data were collected during February 2017. The unit has 15 beds.

\section{Subjects of the study}

The study involved 60 nurses from Pediatric Intensive Care Unit (PICU) at Children's University Hospital in Mansoura city, Egypt.

\section{Tools of data collection}

Structured interview questionnaire sheet was developed by the researcher to collect data based on a review of literature relevant to the problem and by reviewing previous studies (Skillman \&Wischmeyer, (2008), Typpo et al, (2009), Williams, Boyle\& O'Meara, (2010), Wakeham et al, (2013), Bhakta\& Jacobs, (2014),Irving et al , (2015). This tool was measured for content validity by two professors of nursing and two head nurses who had bachelor degree and worked for over 10 years in the above mentioned setting. The data collection form consisting of 4 parts:-

1. Demographics characteristics of study participants included age, level of education, years of experience in the PICU, and number of working hours per week.

2. Perceptions and beliefs of nurses about importance and frequency of growth measurements in the pediatric intensive care units

3. Nurses' perceptions regarding children -specific barriers of growth measurements of critically ill children.

4. Nurses' perceptions regarding nurses -specific barriers of growth measurements of critically ill children.

\section{Statistical analysis}

Statistical analyses were performed with SPSS version 19. For descriptive statistic, frequency and percentage were used. Continuous variables were presented as means and standard deviation. A t-test was used to test for the association and/or difference between categorical variables. A p-value of $<0.05$ was considered statistically significant in all analyses. 


\section{Results}

Table (1) Percentage distribution of nurses according to their characteristics

\begin{tabular}{|c|c|c|}
\hline Items & Frequency & Percent \\
\hline $\begin{array}{l}\text { Age: } \\
\bullet \quad 20-<25 \text { years }\end{array}$ & 27 & 45.0 \\
\hline • $\quad 25-<30$ years & 15 & 25.0 \\
\hline - $\quad 30-\leq 35$ years & 18 & 30.0 \\
\hline $\mathrm{X} \pm \mathrm{SD}$ & \multicolumn{2}{|c|}{$26.44 \pm 4.04$} \\
\hline $\begin{array}{c}\text { Level of education: } \\
\bullet \quad \text { Diploma }\end{array}$ & 2 & 3.3 \\
\hline - Technical institute of nursing & 2 & 3.3 \\
\hline - $\quad$ Bachelor & 55 & 91.7 \\
\hline • Master & 1 & 1.7 \\
\hline Years of experience in the PICU: & 26 & 43.3 \\
\hline - $5-<10$ years & 19 & 31.7 \\
\hline - $\quad \geq 10$ years & 15 & 25.0 \\
\hline $\mathrm{X} \pm \mathrm{SD}$ & \multicolumn{2}{|c|}{$6.45 \pm 3.54$} \\
\hline $\begin{array}{c}\text { Number of working hours per week: } \\
\qquad \quad<30 \text { hours per week }\end{array}$ & 3 & 5.0 \\
\hline - 30 hours $-<40$ hours per week & 43 & 71.7 \\
\hline$\geq 40$ hours per week & 14 & 23.3 \\
\hline $\mathrm{X} \pm \mathrm{SD}$ & \multicolumn{2}{|c|}{$6.69 \pm 1.49$} \\
\hline
\end{tabular}

Table (1) shows that, the age of the highest percent (45\%) of studied nurses were ranged from 20 years to less than 25 years. The majority of them $(91.7 \%)$ had bachelor degree in nursing. In relation to years of experience in the PICU, $43.3 \%$ of them had 5 years of experience in their unit. As regards number of working hours per week, the majority $(71.7 \%)$ of them was working from 30 to less than 40 years per week.

Table (2): Nurses' perceptions and beliefs regarding growth measurements of critically ill children in the pediatric intensive

\begin{tabular}{|c|c|c|}
\hline Items & Frequency & Percent \\
\hline $\begin{array}{l}\text { Importance of growth measurements } \\
\bullet \quad \text { Important }\end{array}$ & 39 & 65.0 \\
\hline • Neutral & 17 & 28.3 \\
\hline - $\quad$ Unimportant & 3 & 5.0 \\
\hline - Unknown & 1 & 1.7 \\
\hline $\begin{array}{l}\text { Growth measurements obtained at admission } \\
\text { • Always }\end{array}$ & 27 & 45.0 \\
\hline • $\quad$ Sometimes & 18 & 30.0 \\
\hline - $\quad$ Never & 3 & 5.0 \\
\hline • Unknown & 12 & 20.0 \\
\hline $\begin{array}{l}\text { Timing of initial measurements (duration after admission) } \\
\qquad \quad<12 \text { hours }\end{array}$ & 38 & 63.4 \\
\hline • $12-24$ hours & 13 & 21.7 \\
\hline - $25-48$ hours & 5 & 8.3 \\
\hline - $\quad$ No specific time & 2 & 3.3 \\
\hline • Unknown & 2 & 3.3 \\
\hline $\begin{array}{l}\text { Timing of subsequent measurements } \\
\text { • Day shift }\end{array}$ & 47 & 78.3 \\
\hline - $\quad$ Evening shift & 7 & 11.7 \\
\hline - $\quad$ Night shift & 5 & 8.3 \\
\hline - $\quad$ Random & 1 & 1.7 \\
\hline - Unknown & 0 & 0.0 \\
\hline $\begin{array}{l}\text { It is important to measure weight daily in infant more than older child? } \\
\text { • Yes }\end{array}$ & 43 & 71.7 \\
\hline$\bullet \quad$ No & 17 & 28.3 \\
\hline $\begin{array}{l}\text { Do you think that length of child' stay in the PICU effect on the importance of taking growth } \\
\text { measurements? } \\
\text { - Yes }\end{array}$ & 37 & 61.7 \\
\hline - $\quad$ No & 23 & 38.3 \\
\hline
\end{tabular}

Table (2) illustrates that, more than two thirds $(65 \%)$ of nurses stated that growth measurements was important, $45 \%$ added that growth measurements were always obtained at admission.63.4\% mentioned that the initial time of measurements is within first 12 hours after admission.And the majority (78.3\%) added that day shift is the appropriate subsequent time of measurements. $71.7 \%$ believed that daily weight measurement in infant is more important than in older child. $61.7 \%$ perceived that length of child' stay in the PICU effect on the importance of taking growth measurements. 


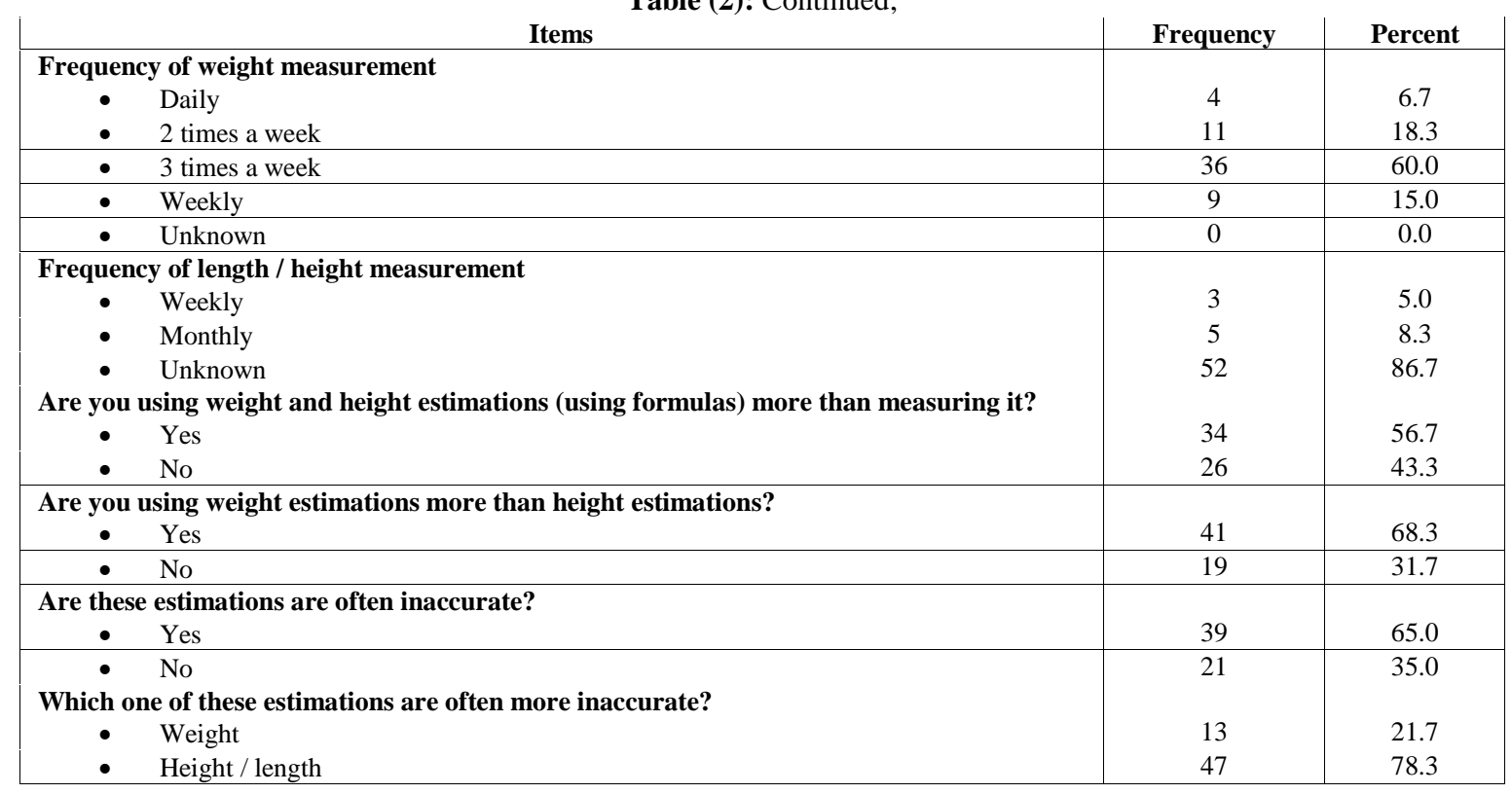

Table (2) continued; clarifies that $60 \%$ stated that they measure weight three times a week. $86.7 \%$ they don't know the frequency of height measurement in their unit. Most of the nursesusing weight and height estimations especially weight estimation. $65 \%$ mentioned that these estimations are often inaccurate especially height estimation.78.3\%

Figure (1): Nurses' perceptions regarding child - specific barriers of growth measurements of critically ill children

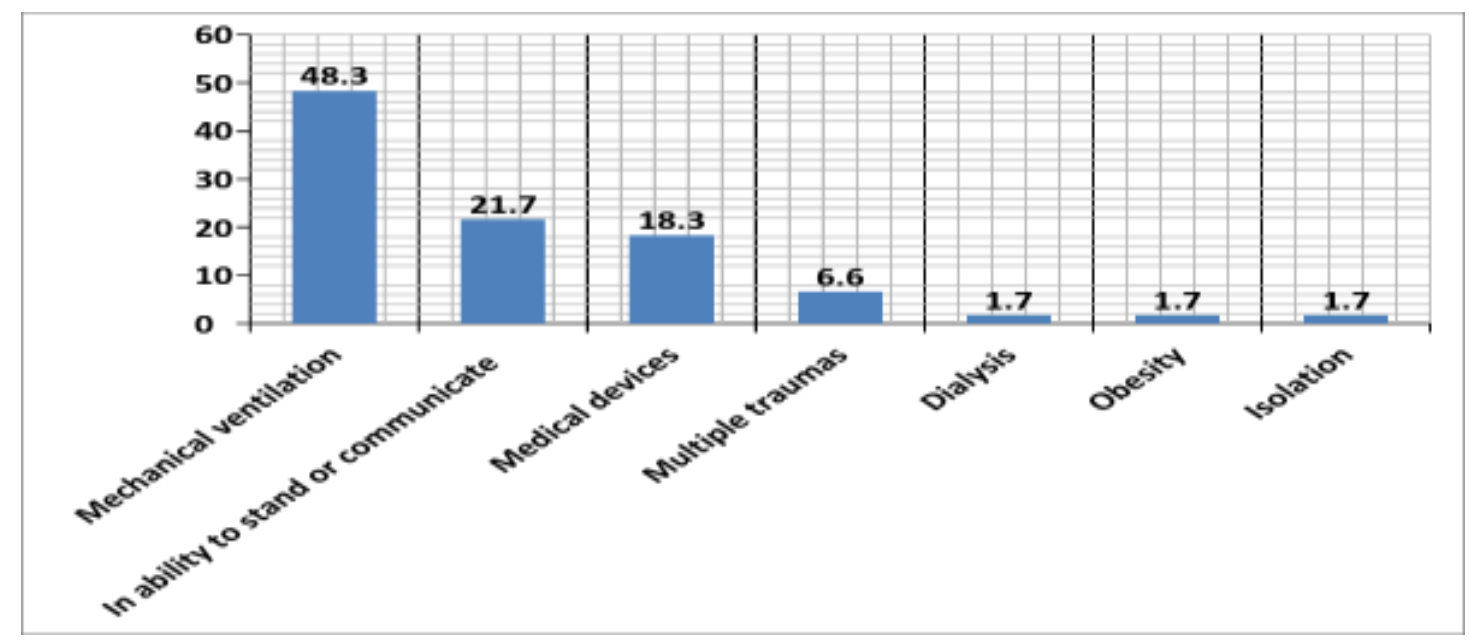

Figure (1)

It was observed from this figure that, the most perceived barrier mentioned by nurses regarding child- specific barriers of growth measurements of critically ill children was mechanical ventilation followed by in ability of the child to stand or communicate. 
Figure (2): Nurses' perceptions regarding nurse - specific barriers of growth measurements of critically ill children

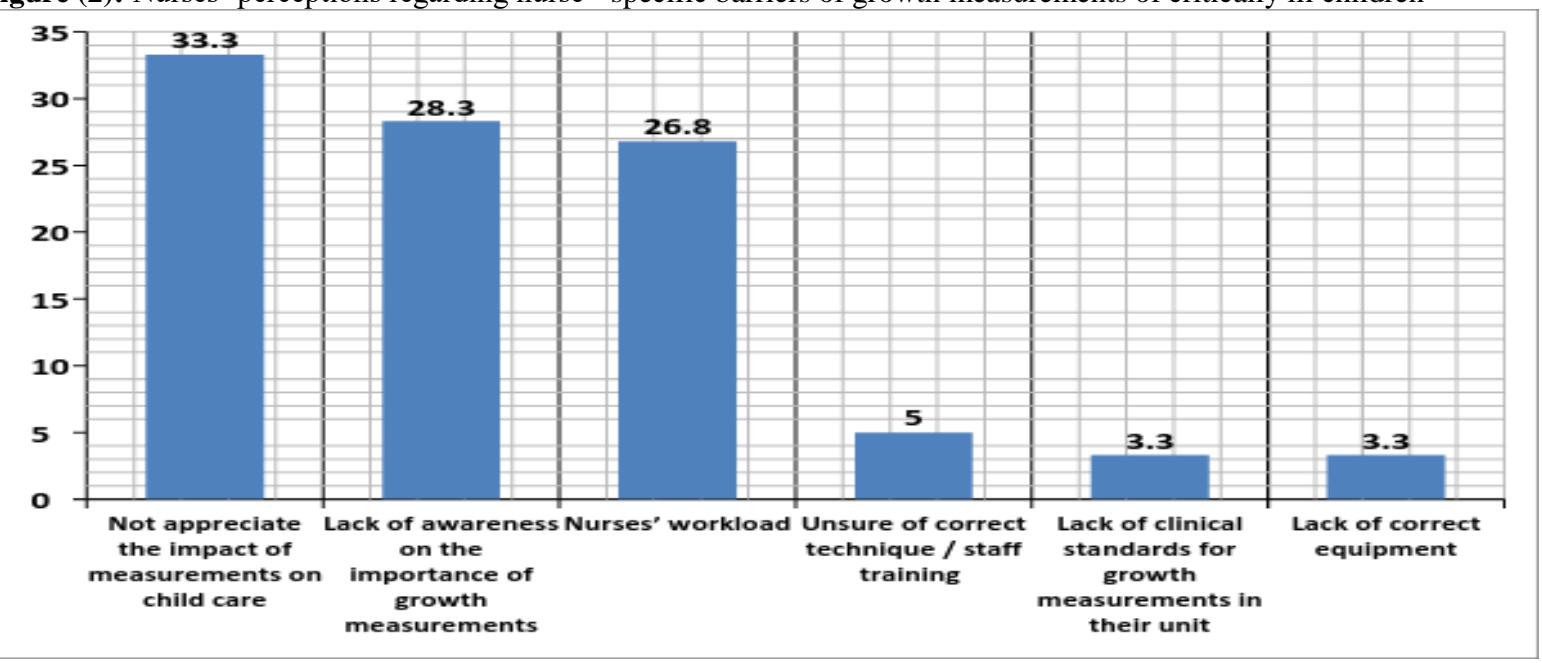

This figure clarifies that;lack of awareness on the importance of growth measurements and its impact on child care and nurses' workload are the most perceived barriers reported by nurses regardingnurse - specific barriers of growthmeasurements of critically ill children.

Table (5): Relationship between nurses' characteristics and their perceptions regarding barriers of growth measurements of critically-ill children

\begin{tabular}{|c|c|c|c|c|c|}
\hline \multicolumn{2}{|c|}{ Nurse - specific barriers } & \multicolumn{2}{|c|}{ Child - specific barriers } & \multirow{2}{*}{\multicolumn{2}{|c|}{ Nurses' characteristics }} \\
\hline P value & T test & $P$ value & $T$ test & & \\
\hline .000 & $.552 * *$ & .004 & $.433 * *$ & & Age \\
\hline .020 & $.357 *$ & .002 & $.459 * *$ & 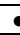 & Level of education \\
\hline .000 & $.567 * *$ & .001 & $.503 * *$ & - & Years of experience in the PICU \\
\hline .030 & $.305^{*}$ & .001 & $.521 * *$ & - & Number of working hours per week \\
\hline
\end{tabular}

This table clarifies that;there is significant relationship between nurses' characteristics and their perceptions regarding barriers of growth measurements of critically-ill children

\section{Discussion}

Child's weight and height measurements are used regularly within the critical care setting whether for calculation of medication dosages, defibrillation, nutritional intake, equipment sizing, and other invasive procedures such as intubation drug doses (Wigfull et al, (2005). Accurate estimation of these measurements is skills expected of all healthcare clinicians, especially nurses. It is necessary because patients may be unable to communicate such information due to unconsciousness or an altered state of conscious (Williams, Boyle\& O'Meara, 2010).In the critical situation there are limitations in acquiring actual weight or height and parents are often not present to provide this information. Moreover, visual estimation of the child's weight or height by nurses is prone to error (O'Leary et al, 2017). So, this study aimed to assess nurses' perception regarding barriers of growth measurements of critically-ill children in the pediatric intensive care unit.

The results of the present study clarified that, more than two thirds of nurses thought that growth measurements was important, obtained at admission and day shift is the appropriate subsequent time of measurements. These results are supported withBhakta\& Jacobs, (2014) who mentioned that, weight is often measured as soon as possible upon admission to the unit for use as baseline information for care delivery. Whereas, these results are not in the same line withthe results of (Irving et al, 2015) who reported that nurses thought that anthropometric measurements were less important, few thought that such measurements are obtained on admission to the PICU and most anthropometric measurements occurred on the night shift. This finding is surprising because the core of nursing practice is to optimize delivery of care while balancing the risks and benefits of specific assessments and interventions. This practice may be an important or potential barrier to consider in achieving higher compliance with obtaining measurements; patients or patients' families may be sleeping and more likely to refuse measurements at night. Moreover, Grippa et al, (2017) added that accurate weight and height is not obtained in all patients admitted to the PICU.

The respondents in the study of Garner, Panpanich\& Logan, (2000) perceived the need to obtain daily weights in infants and weekly weights in older children. This finding appears to acknowledge providers' concerns about growth in infants, but the concern may be misplaced because weights obtained at less frequent intervals will establish trends in weight change and may be equally effective for tracking adequate growth. The findings of this study support this recommendation because the majority believed that daily weight measurement in infant is more important than in older child.

It was found in this study that, about two thirds of nurses perceived that length of child' stay in the PICU effect on the importance of taking growth measurements. This is confirmed with Typpo et al, (2009) who reported that, during an average PICU admission, with median length of stay less than 3 days, the focus should not be on growth or weight gain, but, care should be directed toward stabilization of weight and resolution of the acute illness with minimal decrease in muscle mass. 
The majority of the respondents in this study don't know the frequency of height measurement in their unit and perceived height measurement is less important than weight. This result is supported with Umoh et al, (2008) who suggest that height is not routinely used in critical care sitting.In addition,Anzueto et al, (2011) mentioned that, height measurement is not a daily routine in all PICUs. Although recumbent child' height can be measured by means of a metric ribbon tape, this measurement is not always performed or may lack consistency. Moreover,L'her et al, (2016) added that knowledge of patients' height is essential for daily practice in the intensive care unit. However, actual height measurements are unavailable on a daily routine in the ICU and measured height in the supine position and/or visual estimates may lack consistency.

The finding of the present study revealed that most of the nursesusing weight and height estimations especially weight estimation and mentioned that these estimations are often inaccurate especially height estimation. These findings are supported with Maskin et al, (2010) who mentioned that critical care nurses use height and weight estimates, but these estimations have yet been demonstrated as significantly inaccurate for individual observers and added that estimations of patient's weight made by intensive care unit staff are often inaccurate. In contrast, estimations of height are usually adequate. Ali, Sammy \&Nunes, (2012) added that in many cases it is impractical to weigh seriously ill children; it then becomes necessary to estimate the weight. While Krieser et al, (2007) and Dunne \& Hickey, (2012):stated thataccurate estimation of a child's weight is often necessary but may not always be possible, particularly in the critically ill children.

In relation to nurses' perceptions regarding barriers of growth measurements of critically ill children, the current study found that the most perceived barriers mentioned by nurses were mechanical ventilation, in ability of the child to stand or communicate,lack of awareness on the importance of growth measurements and its impact on child care and nurses' workload. These results are in agreed withthe opinions of other researchers as illustrated in the following; Hulst et al, (2004) stated that although anthropometry is the best tool currently available for assessing critically ill children, it's difficult to be performed. Additionally, Bloomfield et al, (2006) mentioned that actual measurement of weight and height on critically ill patients are not always accomplished because those patients are frequently admitted as emergencies, are not ambulant, or may be unable to communicate, and these factors, in combination, can make accurate estimation or measurements difficult.Furthermore,Skillman \&Wischmeyer, (2008) stressed on the lack of awareness on the importance of appropriately performing measurement and nurses may not fully appreciate the importance of these measurements and their impact on patient care. Wells, (2009) added that accurate weight measurement is often impossible in critical situation because of spinal immobilization precautions, ongoing CPR, emergent airway management or other acute medical interventions, the additional emotional stress and cognitive load of PICU nursing staff make the risk of experiencing errors and these errors are more likely to result in adverse events in the very young patient and the critically ill or injured child or infant with significant physiological insult.Moreover,Buckley et al, (2012) pointed that patients in emergency settings are unable to stand to be weighed accurately or clearly state their most recent weight.Menezes, Leite\&Nogueira, (2012) mentioned thatcritically ill children are bedridden, posing a challenge to take accurate height measurements. Finally,L'her et al, (2016) added that measurement is difficult to achieve by a single operator on a bed-ridden patient, especially in case of body distortion, obesity, and other physiological conditions.

\section{Conclusion}

The study concluded that the most perceived barriers mentioned by nurses were mechanical ventilation, in ability of the child to stand or communicate,lack of awareness on the importance of growth measurements and its impact on child care and nurses' workload.

\section{Recommendations}

In the light of findings of the current study, the following recommendations are suggested:

- More work is required to validate alternative methods and formulae of growth measurements to calculate child's weight and height which can be used in critically ill children.

- Ready availability of appropriate tools and equipment, and well-trained staff will greatly enhance the ability to obtain growth measurements in critically ill children.

- Emphasis on the importance for educating nurses about the importance of obtaining timely growth measurements of children in the PICU.

- Develop strategies with evidence-based guidelines and practice standards which necessary to overcome myths about common barriers of growth measurements in the PICU.

- PICU settings should involve unit-specific registered dieticians, whose presence and involvement in child care is likely to strongly influence perceptions of growth measurements.

- Future surveys and quality improvement projects should be further explore the aspect of specific examples of nursing errors or harm to children related to lack of obtaining accurate growth measurements in PICU children.

- Repeat the study on a large sample size and in different settings of PICU to perform more detailed analysis to evaluate perceived barriers and generalize the results.

- Repeat the study using other research design and tools of data collection including observational checklist to avoid disparity between what is perceived and what is actually carried out in the PICU.

\section{References}

[1] Ali, K, Sammy,I.\&Nunes,P.(2012): Is the APLS formula used to calculate weight-for-age applicable to a Trinidadian population? BMC Emergency Medicine, 12:9.

[2] Anzueto, A., Frutos-Vivar, F., Esteban, A., Bensalami, N., Marks, D., Raymondos, K., Apezteguía, C., Arabi, Y., Hurtado, J., González, M., Tomicic, V., Abroug, F., Elizalde, J., Cakar, N., Pelosi, P. \& Ferguson, N.D. (2011): Ventila group: influence of body mass index on outcome of the mechanically ventilated patients. Thorax; 66:66-73.

[3] Bhakta, R.T, Jacobs, B.R. (2014): Diet and nutrition in critically ill children. In: Rigby MR, Graciano AL, eds. Current Concepts in Pediatric Critical Care: 2014 ed. Mount Prospect, IL: Society of Critical Care Medicine: 115-123. 
[4] Bloomfield, R., Steel,E., MacLennan,G. \&Noble,D.(2006): Accuracy of weight and height estimation in an intensive care unit: Implications for clinical practice and research. Crit Care Med. 34(8):2153-2157.

[5] Buckley, R.G et al. (2012): Bedside Method to Estimate Actual Body Weight in the Emergency Department. Journal of emergency medicine; 42(1):100-104.

[6] Dunne,K.\&Hickey,S.(2012): Accuracy of height and weight estimation by critical care staff. Critical Care; 16(Suppl 1): 523.

[7] Garner, P., Panpanich, R. \& Logan, S. (2000): Is routine growth monitoring effective? a systematic review of trials. Arch Dis Child; 82 (3):197-201

[8] Graves, L., Chayen., G, Peat, J. \& O'Leary, F. (2014): A comparison of actual to estimated weights in Australian children attending a tertiary children's' hospital, using the original and updated APLS, Luscombe and Owens, Best Guess formulae and the Broselow tape. Resuscitation; 85(3):392-6.

[9] Grippa,R.B., Silva,P.S., ElianaBarbosa,E. Bresolin,N.L., Nilesh M. Mehta,M.N.\&Moreno,Y.(2017): Nutritional status as a predictor of duration of mechanical ventilation in critically ill children. Nutrition; 33:91-95.

[10] Hulst,J., Joosten,K.,Zimmermann,L., Hop,W., Buuren,S., Buller,H.,Tibboel,D., Goudoever,J.(2004): Malnutrition in critically ill children: from admission to 6 months after discharge. Clinical Nutrition; 23: 223-232

[11] Irving,S., Seiple, S., Nagle, M.,, Falk, S.,Mascarenhas,M.. \&Srinivasan, V. (2015): Perceived Barriers to Anthropometric Measurements in Critically Ill Children. AJCC American Journal of Critical Care, 24 (6):e99- e107.

[12] Krieser,D., Nguyen,K., Kerr,D., Jolley,D., Clooney,M., Kelly,A.(2007): Parental weight estimation of their child's weight is more accurate than other weight estimation methods for determining children's weight in an emergency department? Emerg Med J; 24:756 -759

[13] L'her,E., Martin-Babau,J. \& François Lellouche,F.(2016): Accuracy of height estimation and tidal volume setting using anthropometric formulas in an ICU Caucasian population. Ann. Intensive Care; 6:55

[14] Lellouche, F., Dionne, S., Simard, S., Bussières, J. \&Dagenais, F. (2012): High tidal volumes in mechanically ventilated patients increase organ dysfunction after cardiac surgery. Anesthesiology; 16:1072-1082.

[15] Martin, J.H., Fay, M.F., Udy, A., Roberts, J., Kirkpatrick, C., Ungerer, J. \&Lipman, J. (2011): Pitfalls of using estimations of glomerular filtration rate in an intensive care population. Intern Med J; 41:537-543.

[16] Maskin L.P., Attie, S., Setten, M., Rodriguez, P.O., Bonelli, I., Stryjewski, M.E. \&Valentini, R. (2010): Accuracy of weight and height estimation in an intensive care unit. Anaesth Intensive Care; 38:930-934.

[17] Menezes, F., Leite, H.P\& Koch Nogueira, P.C. (2012): Malnutrition as an independent predictor of clinical outcome in critically ill children. Nutrition; 28:267-270.

[18] Nasiri,E.\& Nasiri,R.(2013): Accuracy of estimation of total body weight by legs and head weight measuring and comparison method in the anesthetized patients. Anesth Essays Res; 7(3): 341-345.

[19] Neto, A.S., Cardoso, S.O., Manetta, J.A, Pereira, V.G.M., Espósito, D.C., Pasqualucci, M.D.O., Damasceno, M.C.\& Schultz, M.J.(2012): Association between use of lung-protective ventilation with lower tidal volumes and clinical outcomes among patients without acute respiratory distress syndrome: between use of lung-protective ventilation

[20] O’Leary,F., John-Denny,B., McGarvey,K.,Hann,A., Pegiazoglou,I.\&Peat,J.(2017): Estimating the weight of ethnically diverse children attending an Australian emergency department: a prospective, blinded, comparison of age-based and length-based tools including Mercy, PAWPER and Broselow. Arch Dis Child; 102:46-52.

[21] Partridge, R.L., Abramo, T.J., Haggarty, K.A, et al. (2009): Analysis of parental and nurse weight estimates of children in the pediatric emergency department. PediatrEmerg Care; 25(12):816-818.

[22] Sentongo, T. (2010): Growth assessment and monitoring. In: Corkins M, ed. The A.S.P.E.N. Pediatric Nutrition Support Core Curriculum. Silver Spring, MD: American Society for Parenteral and Enteral Nutrition.pp:143-148.

[23] Skillman, H.E. \&Wischmeyer, P.E. (2008): Nutrition therapy in critically ill infants and children. J Parenter Enteral Nutr; $32: 520-34$

[24] Typpo, K.V, Petersen, N.J, Hallman, D.M, Markovitz, B.P. \&Mariscalco, M.M. (2009): Day 1 multiple organ dysfunction syndromes is associated with poor functional outcome and mortality in the pediatric intensive care unit. PediatrCrit Care Med; 10(5):562-570.

[25] Umoh, N.J, Fan, E, Mendez-Tellez, P.A, Sevransky, J.E, Dennison, C.R, Shanholtz, C, Pronovost, P.J. \& Needham, D.M. (2008): Patient and intensive care unit organizational factors associated with low tidal volume ventilation in acute lung injury. Crit Care Med; 36:1463-1468

[26] Wakeham, M, Christensen, M, Manzi J, et al. (2013): Registered dietitians making a difference: early medical record documentation of estimated energy requirements in critically ill children is associated with higher daily energy intake and with use of enteral route. J AcadNutr Diet; 113(10):1311-1316.

[27] Wells, M. (2009): Weight prediction in children in the emergency department. A research report submitted to the Faculty of Health Sciences, University of the Witwatersrand, in partial fulfillment of the requirements for the degree of Master of Science in Medicine in Emergency Medicine. Johannesburg.

[28] Wigfull, J et al. (2005): Critical assessment of haemodynamic data. ContinEducAnaesthCrit Care Pain, 5: 84-88.

[29] Williams,B., Boyle,M.\& O'Meara,P.(2010): Can Undergraduate Paramedic and Nursing Students Accurately Estimate Patient Age and Weight? Pre hospital and Disaster Medicine; 25(2):171-177 